\title{
Liposarcoma of the Testis and Spermatic Cord
}

\author{
Ha Na Lee ${ }^{1}$, Min Su Kim ${ }^{2}$ \\ ${ }^{1}$ Department of Urology, Ewha Womans University Medical Center Seoul Seonam Hospital, Seoul, South Korea \\ ${ }^{2}$ Department of Urology, Seoul Medical Center, Seoul, South Korea \\ Email: cau1004@naver.com
}

Received December 27, 2012; revised February 1, 2013; accepted February 10, 2013

Copyright (C) $2013 \mathrm{Ha} \mathrm{Na}$ Lee, Min Su Kim. This is an open access article distributed under the Creative Commons Attribution License, which permits unrestricted use, distribution, and reproduction in any medium, provided the original work is properly cited.

\begin{abstract}
Primary liposarcoma of the spermatic cord is rare, and preoperative diagnosis is difficult. We report a rare case of well-differentiated liposarcoma in 65-year-old man. The patient's chief complaint was painless enlargement of a mass in the right inguinal area that had persisted for about two months. The main component of the mass was wrapped around the spermatic cord and several components were around the testis. Ultrasonography of the main component showed mixed echogenicity. CT showed an ovoid fat-containing nodule and several other fat-density masses surrounding the testis. The mass was surgically removed, along with the right testis and spermatic cord. A pathological examination showed a well-differentiated liposarcoma of the right spermatic cord and testis.
\end{abstract}

Keywords: Liposarcoma; Testis; Spermatic Cord

\section{Introduction}

Sarcomas of the genitourinary tract account for nearly $2 \%$ of all urologic tumors. The spermatic cord is the most commonly involved urologic site, and accounts for approximately $30 \%$ of all genitourinary sarcomas [1-3]. Liposarcomas are malignant neoplasms of adipose tissue arising from primitive mesenchymal cells. In almost $70 \%$ of cases, they are located in the extremities and the retroperitoneum. The spermatic cord is a rare site of origin, accounting for only $3 \%-7 \%$ of all liposarcoma $[1,4]$. We describe a case of liposarcoma in the testis and spermatic cord and present a literature review of spermatic cord liposarcoma.

\section{Case Report}

A 65-year-old man presented with a painless right inguinal mass that had progressively enlarged for more than two months. Physical examination revealed a $3 \mathrm{~cm}$ mass in the right inguinal area that was soft, irreducible, and non-tender. Serum levels of lactate dehydrogenase, alpha-fetoprotein and human chorionic gonadotropin were within normal ranges. Scrotal ultrasonography with 7-MHz liner array transducers (XP10, Acuson, Mountain View, CA, USA) revealed a heterogeneously hyperechoic mass lesion measuring $2.0 \mathrm{~cm} \times 2.5 \mathrm{~cm}$ in the right spermatic cord (Figure 1). The ultrasound appearance suggested a fat-containing tumor, with the possibility of a lipoma. Computed tomography $(\mathrm{CT})$ revealed a $2.0 \times 2.5$ $\mathrm{cm}$ low-density round main mass in the right spermatic cord and several other fat density masses surrounding the testis (Figures 2(a) and (b)). No obvious lymphadenopathy was identified in the retroperitoneum. The mass was considered a lipoma, but we performed a radical orchiectomy due to the presence of the main mass and several peritesticular masses.

The gross appearance of the specimen revealed a several small, soft, well-circumscribed, fat-containing masses

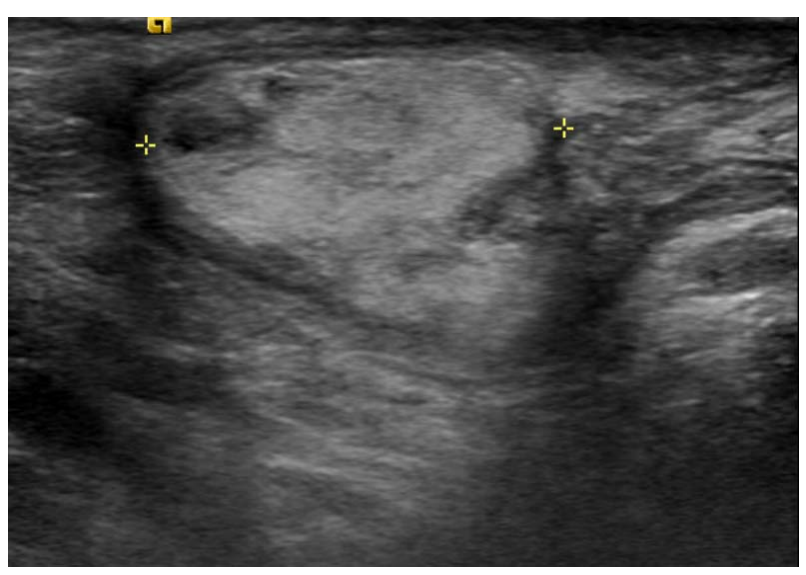

Figure 1. Scrotal ultrasonograpy with 7-MHz liner array transducers revealed a heterogeneously hyperechoic mass lesion measuring $2.0 \times 2.5 \mathrm{~cm}$ in the right spermatic cord, compatible with fat-containing tumor. 


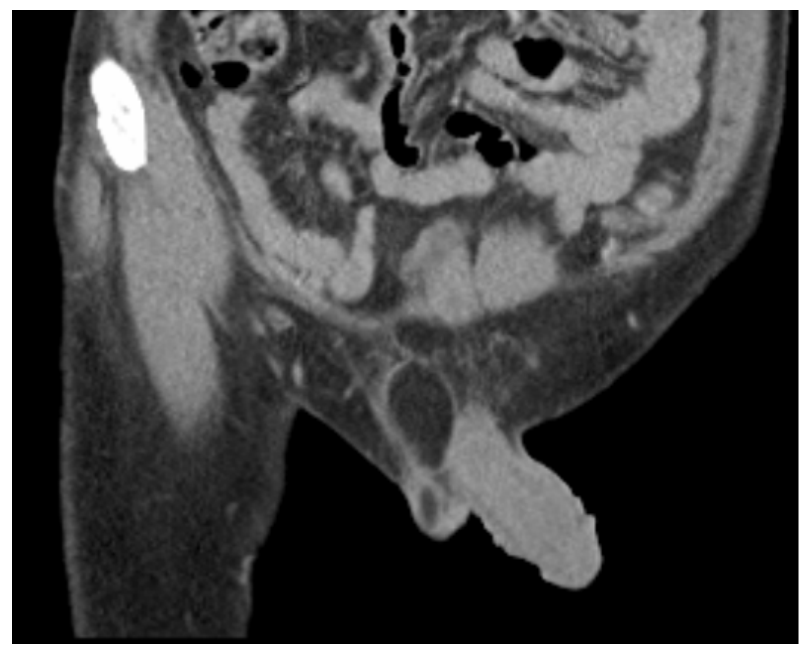

(a)

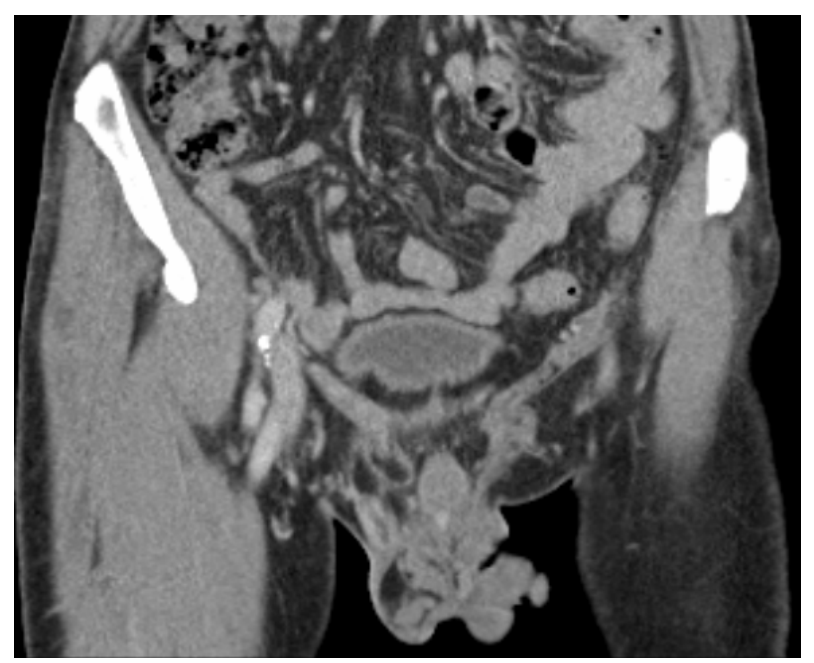

(b)

Figure 2. (a) Sagittal view of CT scan reveals a $2.0 \times 2.5 \mathrm{~cm}$ low-density round main mass in the right spermatic cord and several other fat density mass surrounding testis; (b) Coronal view of CT scan.

adhering to the spermatic cord and testis (Figure 3) that was histopathologically diagnosed as well-differentiated liposarcoma of the spermatic cord and testis (Figure 4). The patient remained free of disease for about 4 years after surgery without any adjuvant therapy.

\section{Discussion}

Liposarcoma of the spermatic cord usually presents as painless scrotal swelling of lipoma-like consistency, progressing in size slowly during a period ranging from months to years, as in the present case. Occasionally, a previously stable mass can rapidly increase in size. The average patient age at presentation is 55 years (range 16.5 - 85) with a slight right preponderance. Fewer than $6 \%$ of cases have histories of scrotal surgery or trauma

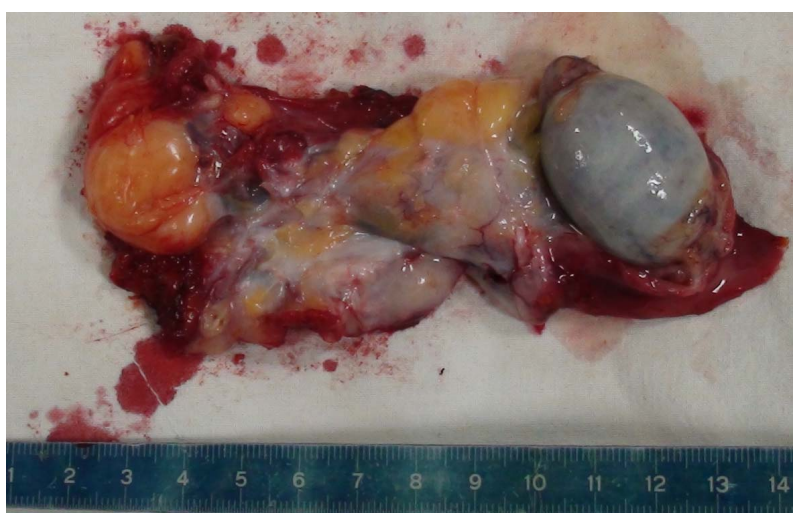

Figure 3. Gross appearance of the specimen revealed a several small, soft, well-circumcised, fat-containing mass adhering to the spermatic cord and testis.

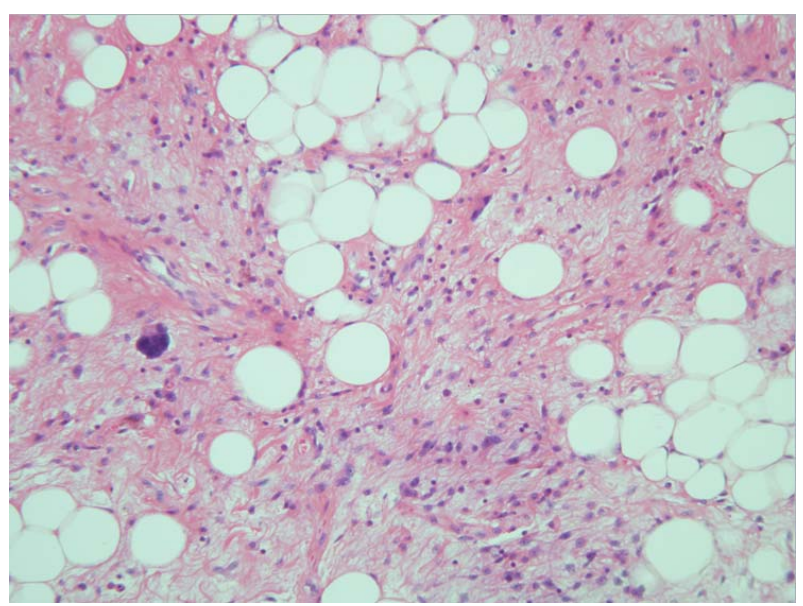

(a)

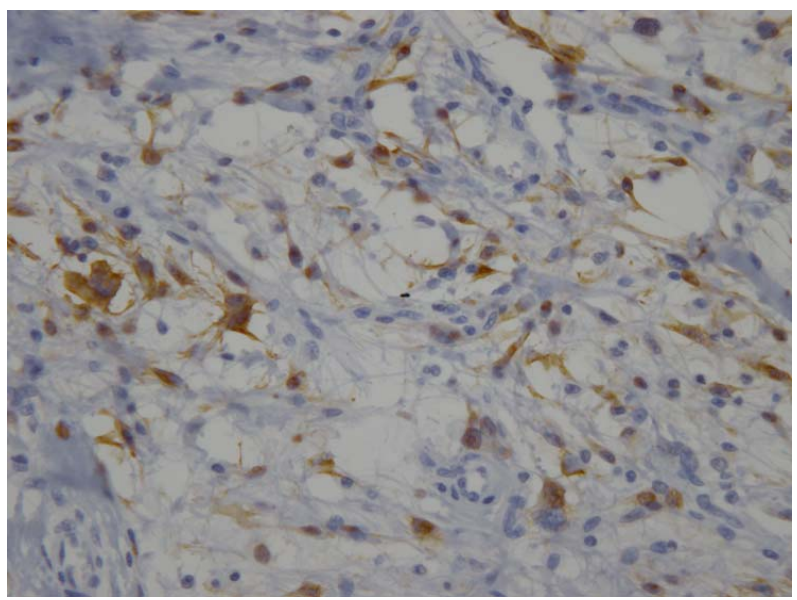

(b)

Figure 4. (a) In High power view, atypical cells having large bizarre nucleus are seen; (b) The atypical cells show positive reaction for immunohistochemical staining of S-100 protein.

[1]. Clinical diagnosis under these conditions may be difficult, since the tumor can easily be mistaken for an 
inguinal hernia, hydrocele or spermatocele, or a tumor of the testis and epididymis [1].

Although liposarcomas are rarely diagnosed preoperatively, ultrasonography, CT and MRI may provide useful information about the lipomatous nature of these masses. The majority of spermatic cord tumors are benign $(70 \%$ $80 \%$ ); lipomas are the most common. Malignant spermatic cord tumors are more frequently sarcomas.

Liposarcomas require radical orchiectomy, while lipomas require only tumor excision. The sonographic findings in our patient suggested that both of the lesions in the hemiscrotum were fat-containing tumors, and that the relatively heterogeneous echogenicity of the lesions was indicative of possible liposarcoma, which prompted further evaluation with CT or MRI. Pleomorphic-type liposarcoma presents as a heterogeneous mass consisting of many hyper and hypoechoic nodules on ultrasonography, which can be distinguished easily from lipoma. However, well-differentiated liposarcomas are composed of fat with thick linear or nodular septa and may be mistaken for lipoma [5].

Spermatic cord liposarcomas are treated by radical orchiectomy [6-10]. Radiation therapy is recommended in addition to surgery for high-grade tumors, lymphatic invasion, inadequate margins, or relapses [11-13]. They usually have good prognoses because of their low levels of malignancy, and relapses tend to be localized. There is a high rate of survival over 5 years. Preoperative diagnosis is infrequent, and suggested by the appearance of a progressively enlarging mass in the scrotum and ultrasonography that shows a solid mass of the spermatic cord that is independent of the testicle.

\section{Conclusion}

Spermatic cord liposarcomas are very uncommon tumors, and are often mistaken for other types of tumors.

\section{REFERENCES}

[1] S. L. Schwartz, S. J. Swierzewski, V. K. Sondak, et al., "Liposarcoma of the Spermatic Cord: Report of 6 Cases and Review of the Literature," Journal of Urology, Vol. 153, No. 1, 1995, pp. 154-157. doi:10.1097/00005392-199501000-00055
[2] S. A. Akbar, T. A. Sayyed, S. Z. Jafri, et al., "Multimodality Imaging of Paratesticular Neoplasms and Their Rare Mimics," Radiographics, Vol. 23, No. 6, 2003, pp. 1461-1476. doi:10.1148/rg.236025174

[3] J. Coleman, M. F. Brennan, K. Alektiar, et al., "Adult Spermatic Cord Sarcomas: Management and Results," Annals of Surgical Oncology, Vol. 10, No. 6, 2003, pp. 669-675. doi:10.1245/ASO.2003.11.014

[4] Y. Kakuta, N. Kawamura, S. Fukuhara, et al., "Two Cases of Liposarcoma of Spermatic Cord," Hinyokika Kiyo, Vol. 54, No. 2, 2008, pp. 147-150.

[5] F. Aragona, E. Pescatori, E. Talenti, et al., "Painless Scrotal Masses in the Pediatric Population: Prevalence and Age Distribution of Different Pathological Conditions-A 10 Years Retrospective Multicenter Study," Journal of Urology, Vol. 155, No. 4, 1996, pp. 1424-1426.

[6] F. J. C. Fernandez, C. Perez-Seoane, A. Ramos, et al., "Paratesticular Liposarcoma of the Spermatic Cord," Actas Urologicas Espanolas, Vol. 14, No. 3, 1990, pp. 202-204.

[7] E. Godoy, J. Amaya, J. L. Parra, et al., "Paratesticular Tumor. Liposarcoma of the Spermatic Cord," Actas Urologicas Espanolas, Vol. 17, No. 6, 1993, pp. 392-396.

[8] M. H. Torosian and A. J. Wein, "Liposarcoma of the Spermatic Cord: Case Report and Review of the Literature," Journal of Surgical Oncolgy, Vol. 34, No. 3, 1987, pp. 179-181. doi:10.1002/jso.2930340310

[9] L. M. Certo, L. Avetta, J. T. Hanlon, et al., "Liposarcoma of Spermatic Cord," Urology, Vol. 31, No. 2, 1988, pp. 168-170. doi:10.1016/0090-4295(88)90049-0

[10] I. Domsa, C. D. Olinici and D. Crisan, "Spermatic Cord Mixed Liposarcoma. Case Report and Review of the Literature," Romanian Journal of Morphology and Embryology, Vol. 49, No. 1, 2008, pp. 105-109.

[11] J. M. Hassan, S. V. Quisling, W. V. Melvin, et al., "Liposarcoma of the Spermatic Cord Masquerading as an Incarcerated Inguinal Hernia," The American Surgeon, Vol. 69, No. 2, 2003, pp. 163-165.

[12] M. May, M. Seehafer, C. Helke, et al., "Liposarcoma of the Spermatic Cord-Report of One New Case and Review of the Literature," Aktuelle Urologie, Vol. 35, No. 2, 2004, pp. 130-133. doi:10.1055/s-2004-818367

[13] J. L. Soler Soler, A. Z. Gomez, M. R. H. Dominguez, et al., "Liposarcoma of the Spermatic Cord: A Report of a New Case and a Review of the Literature," Actas Urologicas Espanolas, Vol. 23, No. 5, 1999, pp. 447-454. 